\title{
Combined pulmonary and thoracic wall resection for stage III lung cancer
}

\author{
Samir S Shah, Peter Goldstraw
}

\begin{abstract}
Background - Carcinoma of the lung with thoracic wall involvement constitutes stage III disease. The management of patients with this condition is complicated. However, improvement in perioperative care coupled with advances in surgical technique have enabled a more aggressive approach to the problem to be adopted.

Methods - A retrospective review was carried out of 58 patients (40 men) of mean age 63 years who underwent thoracotomy for lung cancer with chest wall invasion between 1980 and 1993.

Results - Chest wall resection was performed in 55 patients $(94.8 \%)$; in three patients the discovery of $\mathrm{N} 2$ disease at operation precluded resection. The TNM status was T3N0M0 in 38 patients, T3N1M0 in 13, and T3N2M0 in seven. Squamous cell carcinoma was the commonest cell type (26 patients). Reconstruction of the chest wall was performed in 29 patients (Marlex mesh in six, Marlex-methacrylate in 22, myocutaneous flap in one patient). The morbidity and mortality were $22.4 \%$ and $3.4 \%$ respectively. Follow up was complete in 51 patients. Nineteen $(37 \cdot 2 \%)$ survived $\geqslant 5$ years. The absolute five year survival for N0 and N1 disease was $44 \cdot 7 \%$ and $38 \cdot 4 \%$, respectively. No patients with N2 disease survived five years.

Conclusions - In patients with carcinoma of the lung and chest wall invasion, combined pulmonary and thoracic wall resection offers the prospect of cure with minimal morbidity and mortality. The prognosis of patients with coexistent N2 disease remains poor.

(Thorax 1995;50:782-784)
\end{abstract}

Keywords: lung cancer, thoracotomy.

Direct chest wall invasion occurs in $2-8 \%$ of patients with carcinoma of the lung. ${ }^{12}$ It is important to identify this group of patients as they constitute a subgroup of stage III disease in whom the prospect of surgical resection and cure is favourable. The present study reviews the results of surgical intervention in all patients with carcinoma of the lung and chest wall invasion seen between 1980 and 1993 at the Royal Brompton Hospital.

\section{Methods}

A retrospective review of all patients who underwent combined pulmonary and thoracic wall resection between 1980 and 1993 was carried out. The patients were subject to a uniform preoperative staging protocol as described previously. ${ }^{3}$ After history taking and physical examination each patient underwent routine blood tests (full blood count, serum electrolytes and liver function tests), chest radiography, and a computed tomographic (CT) scan of the brain, chest, and abdomen. An isotopic bone scan to rule out distant metastases was performed in any patient with unexplained weight loss, anaemia, bone pain, abnormalities in serum calcium or alkaline phosphatase, or a combination of these signs and symptoms. Any discrepancy on the bone scan was further evaluated by skeletal radiographs.

Rigid bronchoscopy was routine in all patients. In addition, cervical mediastinoscopy (supplemented by left anterior mediastinotomy if the tumour was located in the left upper lobe or extended to the left main bronchus) was undertaken in any patient in whom the CT scan of the mediastinum suggested invasion or lymphadenopathy. No patient with a positive mediastinoscopy proceeded to thoracotomy. The staging process continued at thoracotomy in the form of mediastinal nodal dissection of all nodes including those of normal size and consistency. Frozen section examination of nodes was carried out when indicated.

\section{Results}

Fifty eight patients ( 40 men) aged $39-87$ years (median 59, mean 63) without evidence of distal metastases or medical contraindication came to thoracotomy. Nineteen $(32 \cdot 8 \%)$ underwent mediastinoscopy prior to thoracotomy. The histological cell type and TNM classification (according to the International Staging System for Lung Cancer ${ }^{4}$ ) are shown in table 1 .

Resection was undertaken in 55 patients $(94 \cdot 8 \%)$. Three $(5 \cdot 2 \%)$ had extensive nodal

Table 1 Histological cell type and TNM status

\begin{tabular}{lc}
\hline & $\begin{array}{c}\text { No. of patients } \\
(n=58)^{*}\end{array}$ \\
\hline Squamous cell carcinoma & 26 \\
Adenocarcinoma & 17 \\
Pancoast's tumour & 6 \\
Large cell carcinoma & 5 \\
Small cell carcinoma & 2 \\
Atypical carcinoid & 2 \\
pT3N0M0 & 38 \\
pT3N1M0 & 13 \\
pT3N2M0 & $7^{*}$ \\
\hline
\end{tabular}

* Includes three patients in whom resection was precluded by the presence of mediastinal lymph node involvement (N2 disease). 
Table 2 Extent of chest wall resection performed

\begin{tabular}{lc}
\hline No. of ribs excised & $\begin{array}{l}\text { No. of patients }(\%) \\
(n=58)\end{array}$ \\
\hline 0 & $3(5 \cdot 2) \dagger$ \\
1 & $4(6 \cdot 9)$ \\
2 & $24(41 \cdot 4)$ \\
3 & $21(36 \cdot 2) \ddagger$ \\
4 & $5(8 \cdot 6)$ \\
5 & $1(1 \cdot 7)$ \\
\hline
\end{tabular}

* The word rib is used for brevity as in most instances segments of ribs were excised.

† Three patients were found to have N2 disease at operation and hence did not proceed to resection.

$\ddagger$ Includes one patient who also underwent partial sternectomy.

Table 3 Type of pulmonary resection performed

\begin{tabular}{lc}
\hline Operation & No. of patients \\
\hline Lobectomy & 37 \\
Bilobectomy & 3 \\
Wedge resection & 4 \\
Sleeve resection & 3 \\
Pneumonectomy & 8 \\
\hline
\end{tabular}

involvement ( $\mathrm{N} 2$ disease) at thoracotomy and were deemed inoperable. In all three patients the preoperative CT scan of the chest was equivocal and mediastinoscopy had been negative. The extent of chest wall resection and type of pulmonary resection performed are shown in tables 2 and 3.

The residual defect required reconstruction in 29 patients (50\%). Marlex mesh was used in six patients and a composite of Marlex and methylmethacrylate in 22 patients. In one patient the Marlex-methylmethacrylate "sandwich" was used in conjunction with a myocutaneous flap (utilising the latissimus dorsi muscle).

There were no operative deaths. The hospital mortality was $3 \cdot 4 \%$ (two patients). The cause of death was progressive respiratory failure in one case and multisystem failure in the second. The morbidity, as defined by a new postoperative complication or clinical/microbiological evidence of infection, was $22 \cdot 4 \%$ (13 patients) - wound infection in six patients, chest infection in five, persistent air leak in one, and atrial fibrillation in one patient.

The period of follow up ranged from 0 to 104 months and was complete in 51 patients $(87 \cdot 9 \%)$. Seven patients were lost to follow up and were omitted from further analysis. In 32 patients recurrent carcinoma was proved or strongly suspected at the time of death, three patients died of unrelated causes, and 16 patients were alive at the time of follow up. None of the late deaths was attributable to the operation. Overall, 19 patients $(37 \cdot 2 \%)$ survived $\geqslant 5$ years. Absolute five year survival with respect to the node status of the patient was $44.7 \%$ (17 patients) and $38.4 \%$ (five patients) for N0 and N1 disease, respectively. No patient with $\mathrm{N} 2$ disease survived five years.

\section{Discussion}

The high mortality and morbidity encountered by surgeons operating on patients with lung cancer invading the chest wall was largely responsible for the pessimistic prognosis ascribed to these patients in the past. ${ }^{5-8}$ The advent of mechanical ventilation and the marked improvement in the perioperative management of the patients did much to revive interest in the role of surgery in the treatment of this condition..$^{9-12}$ Coleman was the first of many investigators to report favourable outcome and long term survival following combined chest wall and pulmonary resection for carcinoma of the lung. ${ }^{213-15}$

The identification of patients with carcinoma of the lung and chest wall involvement, in whom surgical intervention offers the prospects of cure, has been recognised by the new International Staging System for Lung Cancer which divides stage III disease into IIIa and IIIb on the basis of complete resectability. ${ }^{4}$ The operative management of a patient with this condition remains complicated. The need to achieve satisfactory margins of clearance often results in a defect that leaves intrathoracic structures exposed, requires immobilisation to allow adequate chest wall excursion during respiration, and presents a constant risk of bacterial contamination. Furthermore, in all but the most limited resection, or where the resected segment lies entirely beneath the pectoral girdle, some degree of reconstruction is mandatory to prevent respiratory compromise.

The technical aspect of the operation has been aided by two advances. Firstly, the development of prosthetic materials has enabled the structural integrity of the chest wall to be re-established. Although various materials (ranging from stainless steel plates to dura mater) have been utilised previously, these have now been superseded by flexible meshes of different thicknesses and grades. ${ }^{16-19}$ Our preferred choice is Marlex mesh, a single stitch fabric that is rigid in one direction and stretchable in the opposite direction. ${ }^{20}$ The mesh, when sutured to the surrounding skeletal margin, provides a semirigid prosthesis that allows the ingrowth of tissue, thus enabling it to become incorporated into the chest wall. Added rigidity, when dealing with a large defect or the contour of the lateral chest wall, can be obtained by using the mesh in combination with methylmethacrylate as described by McCormack et al. ${ }^{21}$ The second advance has come with the clarification and understanding of the functional anatomy and blood supply of the thoracoabdominal musculature coupled with improvements in microvascular surgical techniques. This has allowed even complex wounds to be managed successfully using a variety of myocutaneous flaps. ${ }^{22}$

The present study highlights several factors that are important to consider in the management of patients with carcinoma of the lung and chest wall invasion. Firstly, the value of accurate preoperative staging cannot be overemphasised. We consider mediastinal exploration mandatory in patients in whom the CT scan of the chest suggests invasion or lymphadenopathy. Mediastinoscopy and left anterior mediastinotomy are associated with minimal complications in experienced hands and have a sensitivity of $91 \%$ and specificity of $100 \% .^{23}$ The need to exclude N2 disease is 
crucial not just in terms of the possibility of resection but also its desirability. Several studies have demonstrated that the presence of N2 disease carries a poor prognosis. ${ }^{142425}$ In the present series no patient with N2 disease survived five years. Careful staging also avoids unnecessary operations. Of the 58 patients who came to thoracotomy, $94.8 \%$ went on to have a resection performed - a figure that is comparable to our experience with both non-small cell and small cell carcinoma of the lung without chest wall involvement. ${ }^{2627}$

The morbidity and mortality in this series were $22.4 \%$ (13 patients) and $3.4 \%$ (two patients) respectively, which compare favourably with other series. ${ }^{24252829}$ Wound infection (six patients) was the most common postoperative problem and in each case this was treated successfully with simple wound toilet and antibiotics. Of the five patients who developed a postoperative chest infection a minitracheostomy for sputum retention was inserted in one patient and one required intermittent positive pressure ventilation. The latter died of progressive respiratory failure. The second death occurred in a patient who had a stormy postoperative course and died of multisystem failure. The absence of major complications and the low mortality rate is a reflection both of rigorous preoperative assessment and of the important advances that have been made in the postoperative care of patients. It stresses the need for a multidisciplinary approach to the management of these patients involving a team of anaesthetists/ intensivists, physiotherapists and nursing staff fully conversant with the condition and the procedure. In addition, plastic surgeons are routinely involved in the preoperative planning whenever an extensive resection is being contemplated, although to date only one patient has required a myocutaneous flap.

None of the operations in our series was undertaken purely for palliation. The reasons for this are threefold: firstly, the success of the operation in terms of achieving symptom control, such as relief of chest wall pain, has been variable; secondly, the prognosis for a patient in whom a complete resection has not been possible is generally poor; and thirdly, the operation itself is a major procedure carrying with it not insignificant morbidity. ${ }^{122128}$

The place of adjuvant therapy in these patients remains unclear. Most attention has centred on the role of radiotherapy, and although Patterson et al reported an improved survival and lower local recurrence rate in patients who received radiation, the results were not significant. Other studies have found no difference in long term survival with the use of postoperative radiotherapy. ${ }^{142425}$ Clearly adjuvant therapy, both in terms of radiotherapy and chemotherapy, in patients with these tumours merits further evaluation. As far as the present series is concerned, we have no uniform policy with respect to adjuvant therapy largely due to the fact that, being a tertiary referral centre, the patients referred to us are under the care of colleagues with differing opinions on the subject.

In conclusion, we believe that combined pulmonary and thoracic wall resection offers the prospects of cure in an important subgroup of patients with stage III lung cancer if $\mathrm{N} 2$ nodes are not involved. Furthermore, with careful preoperative assessment and a multidisciplinary approach to postoperative care this can be achieved with minimal morbidity and mortality.

1 Geha AS, Bernatz PE, Woolner LB. Bronchogenic carcinoma involving the thoracic wall. Surgical treatment and prognostic significance. $₹$ Thorac Cardiovasc Surg 1967; prognostic sign

2 Grillo HC, Greenburg JJ, Wilkings EW Jr. Resection of bronchogenic carcinoma involving the thoracic wall. $\mathcal{F}$ Thorac Cardiovasc Surg 1966;51:417-21.

3 Spiro SG, Goldstraw P. The staging of lung cancer. Thorax 1984;39:401-7.

4 Mountain CF. A new international staging system for lung cancer. Chest 1986;89:225-33S.

5 Threkel JB, Adkins RB Jr. Primary chest wall tumors. Ann Thorac Surg 1971;11:450-9.

6 Teitelbaum SL. Tumors of the chest wall. Surg Gynecol Obstet 1969;129:1059-73.

7 Martini N, Starzynski TE, Beattie EJ Jr. Problems in chest wall resection. Surg Clin North Am 1969;49:313-22

8 Parham FW. Thoracic resection for tumors growing from the bony wall of the chest. Trans South Surg Gynecol Assoc 1898;11:223-363.

9 Rixford E. Excision of portions of the chest wall for malig nant tumors. Ann Surg 1906;53:35-47.

10 Hedblom CA. Tumors of the bony chest wall. Arch Surg 1921;3:56-85.

11 Harrington SW. Surgical treatment of intrathoracic tumors and tumors of the chest wall. Arch Surg 1927;14:406-29.

12 Starzynski TE, Snyderman RK, Beattie EJ Jr. Problems of major chest wall reconstruction. Plast Reconstr Surg 1969; 44:525-35.

13 Coleman FP. Primary carcinoma of the lung with invasion of the ribs. Pneumonectomy and simultaneous block resection of the chest wall. Ann Surg 1947;126:156-68.

14 Ramsey HE, Cliffton EE. Chest wall resection for primary carcinoma of the lung. Ann Surg 1968;167:342-51.

15 Piehler JM, Pairolero PC, Weiland LH, Offord KP, Payne WS, Bernatz PE. Bronchogenic carcinoma with chest wall invasion: factors affecting survival following en bloc resection. Ann Thorac Surg 1982;34:684-91.

16 Cotton BH, Paulsen GA, Dykes J. Prosthesis following excision of chest wall tumor. $\mathcal{F}$ Thorac Surg 1956;31:45-59.
expen

17 Hardin CA, Kittle FC. Repair of surgical defects of the chest wall with a fiberglass prosthesis. Ann Surg 1956;22: 139-52.

18 Rees TD, Converse JM. Surgical reconstruction of defects of the thoracic wall. Surg Gynecol Obstet 1965;121:1066-72.

19 McCormack PM. Use of prosthetic materials in chest-wal reconstruction. Surg Clin North Am 1989;69:965-76.

20 Graham J, Usher F, Perry JL, Barkley H. Marlex mesh as a prosthesis in the repair of thoracic wall defects. Ann Surg 1960;151:469-78.

21 McCormack P, Bains MS, Beattie EJ Jr, Martini N. New trends in skeletal reconstruction after resection of chest trends in skeletal reconstruction after resection

22 Tobin GR, Mavroudis C, Howe WR, Gray LA Jr. Reconstruction of complex thoracic defects with myocutaneous and muscle flaps. $\mathcal{F}$ Thorac Cardiovasc Sur 1983;85:219-28.

23 Luke GP, Pearson FG, Todd TR, Patterson GA, Cooper JD. Prospective evaluation of mediastinoscopy for assessment of carcinoma of the lung. $\mathcal{F}$ Thorac Cardiovasc Surg 1986;91:53-6.

24 Patterson GA, Ilves R, Ginsberg RJ, Cooper JD, Todd TRJ, Pearson FG. The value of adjuvant radiotherapy in pulmonary and chest wall resection for bronchogenic in pulmonary and chest wall resection for bro

25 Paone JF, Spees EK, Newton CG, Lillemoe KD, Kieffer RF, Gadacz TR. An appraisal of en bloc resection of peripheral bronchogenic carcinoma involving the thoracic wall. Chest 1982;81:203-7.

26 Gaer JA, Goldstraw P. Intraoperative assessment of nodal staging at thoracotomy for carcinoma of the bronchus. Eur $\mathcal{f}$ Cardiothorac Surg 1990;4:207-10.

27 Shah SS, Thompson J, Goldstraw P. Results of operation without adjuvant therapy in the treatment of small cell lung cancer. Ann Thorac Surg 1992;54:498-501.

28 McCaughan BC, Martini N, Bains MS, McCormack PM. Chest wall invasion in carcinoma of the lung. Therapeutic and prognostic implications. $\mathcal{F}$ Thorac Cardiovasc Surg and prognostic imp

29 Allen MS, Mathisen DJ, Grillo HC, Wain JC, Moncure AC, Hilgenberg AD. Bronchogenic carcinoma with chest wall invasion. Ann Thorac Surg 1991;51:948-51. 